Universität Zürich

Zentrum für Zahnmedizin

Klinik für Präventivzahnmedizin, Parodontologie und Kariologie (PPK)

Direktor: Prof. Dr. med. dent. Thomas Attin

Arbeit unter Leitung von Prof. Dr. med. dent. Dr. rer. biol. hum. Albert Mehl

\title{
Trueness of four different milling procedures used in dental CAD/CAM systems
}

\author{
INAUGURAL-DISSERTATION \\ zur Erlangung der Doktorwürde der Zahnmedizin \\ an der Medizinischen Fakultät \\ der Universität Zürich
}

vorgelegt von

Corinna Eva Kirsch

Genehmigt auf Antrag von Prof. Dr. med. dent. Dr. rer. biol. hum. Albert Mehl Zürich 2016 


\section{Publikationshinweis}

Trueness of four different milling procedures used in dental CAD/CAM systems



Journal: $\quad$ Clinical Oral Investigations

http://link.springer.com/article/10.1007\%2Fs00784-016-1916-y 


\title{
Trueness of four different milling procedures used in dental CAD/CAM systems
}

\author{
Corinna Kirsch $^{1} \cdot$ Andreas Ender $^{1} \cdot$ Thomas Attin $^{2} \cdot$ Albert Mehl $^{1}$
}

Received: 8 February 2016/Accepted: 18 July 2016

(C) Springer-Verlag Berlin Heidelberg 2016

\begin{abstract}
Objectives Milling is a crucial step in producing restorations using computer-aided design and computer-aided manufacturing $(\mathrm{CAD} / \mathrm{CAM})$ systems. In this study the trueness of currently available milling devices was evaluated.

Materials and methods Thirty clinical cases (ten inlays, ten crowns, ten onlays) were milled from ceramic blocks using four different milling approaches: five axis with IMES CORiTEC 450i, four axis with CEREC MCXL, four axis with CEREC MCXL-EF and five axis with inLab MCX5. The milled restorations were scanned and the occlusal and inner surfaces compared to the originally calculated 3D surface using difference analysis software. The $(90-10 \%) / 2$ percentile of the distances were calculated and analysed using oneway ANOVA with the post hoc Scheffé test $(\alpha=0.05)$. Chipping of marginal areas were visually examined and analysed using one-way ANOVA with a post hoc Tamhane test $(\alpha=0.05)$.

Results At inner surfaces, the milling trueness of IMES $(33.9 \pm 16.3 \mu \mathrm{m}), \mathrm{X} 5(32.3 \pm 9.7 \mu \mathrm{m})$ and MCXL-EF $(34.4 \pm 7.5 \mu \mathrm{m})$ was significantly better $(p<0.001)$ than that of MCXL $(62.1 \pm 17.1 \mu \mathrm{m})$. At occlusal surfaces, MCXL-EF $(25.7 \pm 9.3 \mu \mathrm{m})$ showed significant higher accuracy $(p<0.001)$ than MCXL $(48.7 \pm 23.3 \mu \mathrm{m})$ and X5
\end{abstract}

Corinna Kirsch

corinna.kirsch@zzm.uzh.ch

1 Division for Computerized Restorative Dentistry, Clinic for Preventive Dentistry, Periodontology and Cariology, Center of Dental Medicine, University of Zurich, 11 Plattenstrasse, 8032 Zurich, Switzerland

2 Clinic for Preventive Dentistry, Periodontology and Cariology, Center of Dental Medicine, University of Zurich, 11 Plattenstrasse, 8032 Zurich, Switzerland
$(40.9 \pm 20.4 \mu \mathrm{m})$. IMES produced the most chipping $(p<0.001)$.

Conclusions Five-axis milling devices yield high trueness. MCXL-EF is competitive and may allow chairside fabrication with good milling results.

Clinical relevance Accurate milling is required for wellfitting restorations and thereby requires fewer manual finishing steps, yields smaller marginal gaps, resistance to secondary caries and longevity of restorations.

Keywords Accuracy · Computer-aided design/ computer-aided manufacturing $(\mathrm{CAD} / \mathrm{CAM}) \cdot$ Fit $\cdot$ Milling . Trueness

\section{Introduction}

Accuracy is crucial in dental practice, particularly regarding the fit of restorations, even if production involves using computer-aided design (CAD) and computer-aided manufacturing (CAM). To improve the outcome of CAD/ CAM-manufactured restorations, all steps in production must be coherent and provide the necessary accuracy [1].

Current CAD/CAM systems comprise three components: scanning, design and manufacturing [2, 3]. In terms of scanning, several studies have shown that, focusing on single preparations or fixed partial denture preparations, digital impressions yield a high accuracy [4-7]. The outputs of the scanning process are point-clouds and triangle meshes, which are used in the second step, the design. There are many options available for adapting the design of the restoration. The morphologies that can be generated by using the biogeneric tooth model provide predictable occlusal contacts and can even be improved using information on dynamics by simulating articulation [8]. The setting of the cement space can be defined 
interactively and adjusted to precise values, and the effect of varying the marginal gap size can be evaluated [9-11]. Therefore, scanning and CAD satisfy the requirements for accuracy and adjustment.

As CAD/CAM restorations are mostly machined out of a material block [3], the milling also needs to be accurate, as it can affect internal fit and thereby marginal gap size [12]. Imperfections at the margins can lead to inflammation of gingival tissue [13]. Increased marginal gap size can result in plaque accumulation and increased potential for microleakage $[9,14]$. In clinical studies, a high rate of secondary caries has been attributed to marginal deficiency $[15,16]$. If milling is performed with adequate accuracy, these disadvantages can be avoided. Another benefit of accurate milling is the reduced need for adaptation at internal surfaces [17], which saves time. Furthermore, by reducing the need for manual finishing steps [3] at internal and occlusal surfaces, artificial material damage can be avoided and the quality of the restoration can be improved [18].

To date, few investigations have focused on milling accuracy. Previous studies have mostly been restricted to analyse the fit of restorations [1, 11, 19-24]. Marginal fit is one of the most crucial aspects of dental restorations [20] and should be assessed [25]. Direct microscopic examination is widely used and values for marginal gaps range between 8 and $206 \mu \mathrm{m}$ [9, 26]. Analysis of cross-sectioned specimens or sectioned lightbodied replicas allows interpretation of internal fit and show values for internal gaps of between 68 and $297 \mu \mathrm{m}$ [11, 12, 23, $27,28]$. The quality of the analysis is correlated to the number of measurement points [29]. Due to the necessary cutting process, there is a loss of information in the analogue twodimensional (2D) replica technique [20], and an evaluation based only on 2D is disadvantageous [30]. Analyses based on micro-computed tomography are also used $[9,31]$. They provide close sectioning and therefore allow a large number of measurement sites. Nevertheless, a digital 3D analysis provides comprehensive results over the complete surface, without data loss [20]. For 3D analysis, either a replica or manufactured specimen is scanned on top of the prepared tooth, followed by a scan of the prepared surface using the same coordinate system [20-22, 32], or the surfaces of the prepared tooth and the manufactured restoration are superimposed by using software [1, 24, 27, 33-35]. Superimposition allows easy comparison between two situations [36]. Likewise, a combination of the replica technique and superimposition by software can be used [37]. Most of the studies using 3D analysis evaluated the fit of the restorations $[1,20-22,27,32,37]$, but not the overall surface quality of the fabrication process itself.

In order to evaluate the quality of the milling process, the entire surface of the milled restoration should be compared to the CAD data set sent to the milling device. To date, few studies have directly examined this kind of milling accuracy
[17]. In the study mentioned before, surfaces of the virtual and milled restoration were directly compared and all milled surfaces, in particular, the inner and occlusal surface, were evaluated. A commonly used chairside milling device was found to achieve a trueness of $61 \pm 22 \mu \mathrm{m}$ for inner surfaces and $55 \pm 18 \mu \mathrm{m}$ for occlusal surfaces, while a five-axis device could achieve a trueness of $41 \pm 15 \mu \mathrm{m}$ for inner and $42 \pm 10 \mu \mathrm{m}$ for occlusal surfaces. Differences in the construction of milling machines and different machining strategies may influence the milling result [38]. In dental offices, three- or four-axis machines are widely used, whereas in milling centres, five-axis machines are more commonly used. The most common machining strategy is the Z-level strategy, where the restoration is milled on the basis of $2 \mathrm{D}$ curves analogous to contour lines [38].

Accuracy involves two factors: trueness and precision. Precision delivers information about the closeness of measurement values to each other. Trueness delivers information about the closeness between measurement values and the true value [39]. The aim of the present study was to analyse the trueness of four actual milling processes, using different devices. The null hypothesis was that there would be no difference concerning milling trueness among the four milling processes.

\section{Materials and methods}

In order to determine an appropriate sample size, power analysis for one-way ANOVA was calculated using R (version 3.1.2; R Foundation for Statistical Computing, Vienna). The significance level was set to 0.05 , power was set to 0.85 and the results of Bosch et al. [17] were used to estimate variance between the groups and within a group. As a result, ten specimens per group were required.

For this study, the restorations of 30 different cases consisting of 10 inlays, 10 partial crowns and 10 full crowns were fabricated using four different milling procedures. In total, 120 restorations have been examined. The 30 clinical cases were randomly selected from the large anonymised database of a dental clinic. The preparations were located at molars (25) and premolars (5) and met the claims for ceramic restorations. Eight inlay preparations involved three surfaces of the tooth, and two inlay preparations involved two surfaces. The preparations for partial crowns varied from three and four involved surfaces to full occlusal coverage always involving at least one cuspid and retaining at least one dental surface. The corresponding preparations had been digitized using an intraoral optical scan system (Cerec Bluecam or Cerec Omnicam; Sirona Dental Systems, Bensheim, Germany).

First, the digital models of the cases were collected from the database, digitally trimmed and stereolithographically fabricated from acrylate polymer (inCoris SL; infiniDent, Sirona Dental Systems) to produce master models for further 
handling. The printed models were slightly powdered (Helling 3D Laserscanning Anti-Glare-Spray; Helling, Heidgraben, Germany) and scanned with a laboratory scanning device (inEos X5, inLab version 4.2.5; Sirona Dental Systems) with several single images of the quadrant. On the digital master models, the preparation margin was defined and restorations were calculated using the following parameters (in $\mu \mathrm{m}$ ): spacer, 80; marginal adhesive gap, 60; occlusal milling offset, 0 ; proximal contact strength, 25; occlusal contact strength, 25; dynamic contact strength, 25; minimal thickness (radial), 0; minimal thickness (occlusal) 0; and margin thickness, 0 . Other parameters were set as follows: consider instrument geometry, no, and remove undercuts, yes. The datasets of the restorations were saved as STL files.

The data were imported into machine-specific CAM modules, where the required instrument geometry and milling strategy, according to the milling machine, was considered. The different milling procedures and instruments are shown in Table 1. All restorations were milled in glass ceramic (VITABLOCS Mark II; Vita Zahnfabrik, Bad Säckingen, Germany) without any further changes to the restoration.

Group IMES was milled using a five-axis milling device CORiTEC 450i (imes-icore, Eiterfeld, Germany) and standard software iCAM V4.6 (imes-icore).

Group MCXL was milled using four-axis milling unit inLab MC XL (Sirona Dental Systems) with inLab version 4.2.5 software (Sirona Dental Systems) and the twostep milling procedure.

Group $M C X L-E F$ was milled using four-axis milling unit inLab MC XL (Sirona Dental Systems) with inLab version 15.0.0 software and a new extra-fine two-step milling procedure.

Group $X 5$ was milled using a five-axis milling unit inLab MC X5 (Sirona Dental Systems) with inLab version 15.0.0 software.
Group MCXL served as control group, as this system has been used frequently before [10-12, 17, 19, 21, 22, 28, 31] and the used milling mode has been examined previously by Bosch et al. [17]. Milling time was reported and an average value for all groups calculated. After milling, the restorations were cleaned, dried and lightly and carefully powdered (Helling 3D Laserscanning Anti-Glare-Spray; Helling) and scanned with the inEos X5 (Sirona Dental Systems) using inLab version 4.2.5 software (Sirona Dental Systems). The milled restorations were scanned from multiple directions to acquire the complete inner and outer surfaces. The 3D surfaces were orientated in a similar direction as used for the previous calculated restorations, and data were exported as STL files.

The scanned 3D surfaces of the milled restorations were compared to the originally calculated 3D surface using difference analysis software (OraCheck version 2.0.1; Cyfex, Zurich, Switzerland). The occlusal or inner region of the two corresponding 3D surfaces were selected and superimposed by the software. After the superimposition, the area of interest was selected and the distances between the surfaces were calculated for each surface point. For each comparison, the distances were exported as CSV files. From all the differences obtained for one comparison, the 10th and 90th percentiles were calculated and the metric value for the deviation was defined as deviation measure $(\mathrm{DM})=(90-10 \%) / 2$ percentile. The DM values were imported for all groups and restorations into statistical analysis software (SPSS 21; IBM, Armonk, NY, US), and the statistical significance of differences between groups and restorations analysed using one-way ANOVA with post hoc Scheffé test $(\alpha=0.05)$.

In order to evaluate the accuracy of the method, two of the milled inlay restorations and two of the milled crown restorations were each scanned three times, including all steps described above. The 3D surfaces of the same restoration were superimposed pairwise onto each other and analysed as
Table 1 Milling procedure and rotary instrument diameters

\begin{tabular}{|c|c|c|c|c|}
\hline Group & Milling unit & $\begin{array}{l}\text { Machine } \\
\text { configuration }\end{array}$ & Milling strategy & $\begin{array}{l}\text { Diameters rotary } \\
\text { instruments }(\mathrm{mm})\end{array}$ \\
\hline IMES & CORiTEC 450i & five axis & $\begin{array}{l}\text { one spindle using different } \\
\text { instruments in z-level }\end{array}$ & $2.5,1.0,0.6$ \\
\hline MCXL & $\begin{array}{l}\text { inLab } \\
\text { MC XL }\end{array}$ & four axis & $\begin{array}{l}\text { two simultaneously moving spindles } \\
\text { two-step: removing last } 300 \mu \mathrm{m} \text { in } \\
\text { second milling step }\end{array}$ & $1.0,1.8$ \\
\hline MCXL-EF & $\begin{array}{l}\text { inLab } \\
\text { MC XL }\end{array}$ & four axis & $\begin{array}{l}\text { two simultaneously moving spindles } \\
\text { two-step: removing last } 100-300 \mu \mathrm{m} \\
\text { in second milling step with } \\
\text { extra-fine instruments }\end{array}$ & $\begin{array}{l}1.0,1.8 \\
0.9,1.1\end{array}$ \\
\hline X5 & $\begin{array}{l}\text { inLab } \\
\text { MC X5 }\end{array}$ & five axis & $\begin{array}{l}\text { one spindle using different } \\
\text { instruments in z-level }\end{array}$ & $2.2,1.4,1.2$ \\
\hline
\end{tabular}


described above. Twelve comparisons were done for the occlusal and inner areas to obtain information about the precision of the measurement method itself.

For further evaluation of the marginal areas, a visual examination was performed. The margins of each restoration were examined for marginal chippings using $2.5 \times$ magnifying glasses (Zeiss GTX; Carl Zeiss, Oberkochen, Germany). Chippings were classified as follows: rate 0 indicates no visible chipping $(<50 \mu \mathrm{m})$, rate 1 indicates that small chippings were visible $(50-100 \mu \mathrm{m})$ and rate 2 indicates that larger chippings $(>100 \mu \mathrm{m})$ were visible. The investigator standardized the rating by visualizing chippings together using the difference analysis software (OraCheck version 2.0.1; Cyfex) and measuring the loss in dimensions. The margin of each restoration was rated in four sections (mesial, buccal, distal and oral), and the overall chipping for the restoration was defined as the highest rate in the four sections of the margin. The chipping values were imported into statistical software (SPSS 21; IBM) and differences analysed for statistical significance using one-way ANOVA with a post hoc Tamhane test $(\alpha=0.05)$.

\section{Results}

The average accuracy of the used evaluation method was $9.1 \pm 5.5 \mu \mathrm{m}$ for the occlusal surface, $13.9 \pm 8.2 \mu \mathrm{m}$ for the inner surface and $11.5 \pm 7.2 \mu \mathrm{m}$ overall.

The means and standard deviations of the (90-10\%) / 2 percentile, used as a parameter of trueness, are listed in Table 2 for the inner surface and in Table 3 for the occlusal surface.

The milling trueness of the inner surface of groups IMES, X5 and MCXL-EF was significantly higher $(p<0.001)$ than group MCXL for overall, inlay and onlay restorations. For the inner surface of crowns, group MCXL-EF was significantly more accurate $(p=0.004)$ than group MCXL. Difference images showing the deviations of the test groups for one onlay restoration are shown in Fig. 1.

The overall trueness of the occlusal surface of group MCXL-EF was significantly higher $(p<0.001)$ than that of groups MCXL and X5. The occlusal surface of inlays showed significantly lower deviations $(p=0.012)$ in group MCXL-EF than that in group MCXL. The occlusal surface of crowns did not show significant differences between the groups. For the occlusal surface of onlays, group MCXL-EF showed significantly higher accuracy $(p=0.031)$ than group MCXL.

The relative frequency of chipping ranks according to the visual examination for all restorations is shown in Fig. 2. In general, group IMES showed significantly $(p<0.001)$ more chippings than all other groups. Inlay restorations showed significantly $(p<0.001)$ more chippings in group IMES than in groups MCXL and MCXL-EF, whereby the chipping rate for MCXL was significantly higher than that for MCXL-EF. For crowns, there were no statistically significant differences among the test groups. For onlays, group IMES showed statistically significantly $(p=0.008)$ more chippings than groups MCXL and MCXL-EF.

The average machining time was $32 \mathrm{~min}$ for group IMES, 15 min for group MCXL, 20 min for group MCXL-EF and 35 min for group X5.

The remaining sprue after milling differed among the four groups (IMES ca. $4 \times 4 \mathrm{~mm}$, MCXL ca. $1 \times 2 \mathrm{~mm}$, MCXL-EF ca. $1 \times 2 \mathrm{~mm}$, X5 ca. $1.5 \times 1.5 \mathrm{~mm}$ ).

\section{Discussion}

The aim of this present study was to analyse the trueness of four different milling procedures independent of other parts of the digital workflow (intraoral scanning and design). Milling trueness differed significantly between the test groups; thus, the null hypothesis had to be rejected. The inner surfaces exhibited higher trueness in groups IMES, MCXL-EF and X5 than in group MCXL. On the occlusal side, group MCXL-EF performed similarly or better than group IMES and group X5, except for the occlusal surfaces of crowns, where no significant differences were seen.

The clinical cases investigated comprised various different preparation designs and geometries, such as full crown preparations, partial crowns and inlays, with differences in the configuration of boxes, depth of cavitations, steepness of walls and angled curvatures. Preparations were made in accordance with the guidelines for ceramic restorations [40]. A wide spectrum of different geometries was delivered; however, the preparation designs were limited to single tooth restorations.
Table 2 Milling trueness (mean, standard deviation) of inner surfaces

\begin{tabular}{lllll}
\hline Restoration & IMES & MCXL & MCXL-EF & X5 \\
\hline Overall & $33.9 \pm 16.3 \mu \mathrm{m}^{\mathrm{a}}$ & $62.1 \pm 17.2 \mu \mathrm{m}^{\mathrm{b}}$ & $34.4 \pm 7.5 \mu \mathrm{m}^{\mathrm{a}}$ & $32.3 \pm 9.8 \mu \mathrm{m}^{\mathrm{a}}$ \\
Inlay & $39.1 \pm 17.1 \mu \mathrm{m}^{\mathrm{c}}$ & $65.6 \pm 17.6 \mu \mathrm{m}^{\mathrm{d}}$ & $36.2 \pm 8.4 \mu \mathrm{m}^{\mathrm{c}}$ & $34.0 \pm 7.5 \mu \mathrm{m}^{\mathrm{c}}$ \\
Crown & $37.3 \pm 20.2 \mu \mathrm{m}^{\mathrm{e}, \mathrm{f}}$ & $55.0 \pm 15.1 \mu \mathrm{m}^{\mathrm{f}}$ & $31.4 \pm 6.4 \mu \mathrm{m}^{\mathrm{e}}$ & $37.6 \pm 10.7 \mu \mathrm{m}^{\mathrm{e}, \mathrm{f}}$ \\
Onlay & $25.2 \pm 5.5 \mu \mathrm{m}^{\mathrm{g}}$ & $65.8 \pm 18.1 \mu \mathrm{m}^{\mathrm{h}}$ & $35.6 \pm 7.5 \mu \mathrm{m}^{\mathrm{g}}$ & $25.4 \pm 7.0 \mu \mathrm{m}^{\mathrm{g}}$ \\
\hline
\end{tabular}

${ }^{\mathrm{a}-\mathrm{h}}$ Subgroups with significant differences between milling modes for a given type of restoration 
Table 3 Milling trueness (mean, standard deviation) of occlusal surfaces

\begin{tabular}{lllll}
\hline Restoration & IMES & MCXL & MCXL-EF & X5 \\
\hline Overall & $33.7 \pm 25.3 \mu \mathrm{m}^{\mathrm{a}, \mathrm{b}}$ & $48.7 \pm 23.3 \mu \mathrm{m}^{\mathrm{b}}$ & $25.7 \pm 9.4 \mu \mathrm{m}^{\mathrm{a}}$ & $40.9 \pm 20.4 \mu \mathrm{m}^{\mathrm{b}}$ \\
Inlay & $37.6 \pm 23.6 \mu \mathrm{m}^{\mathrm{c}, \mathrm{d}}$ & $59.8 \pm 21.7 \mu \mathrm{m}^{\mathrm{d}}$ & $33.4 \pm 10.4 \mu \mathrm{m}^{\mathrm{c}}$ & $53.6 \pm 19.6 \mu \mathrm{m}^{\mathrm{c}, \mathrm{d}}$ \\
Crown & $33.2 \pm 33.0 \mu \mathrm{m}^{\mathrm{e}}$ & $34.5 \pm 13.9 \mu \mathrm{m}^{\mathrm{e}}$ & $18.4 \pm 3.0 \mu \mathrm{m}^{\mathrm{e}}$ & $29.3 \pm 12.0 \mu \mathrm{m}^{\mathrm{e}}$ \\
Onlay & $30.4 \pm 19.5 \mu \mathrm{m}^{\mathrm{f}}$ & $51.6 \pm 26.7 \mu \mathrm{m}^{\mathrm{f}}$ & $25.4 \pm 6.2 \mu \mathrm{m}^{\mathrm{g}}$ & $39.9 \pm 21.9 \mu \mathrm{m}^{\mathrm{f}}$ \\
\hline
\end{tabular}

${ }^{\mathrm{a}-\mathrm{f}}$ Subgroups with significant differences between milling modes for a given type of restoration
The evaluation method used is bound to the scan accuracy of the extra-oral scanner. Characteristics, such as depth, steepness and multiple-angled curvatures, may influence scan accuracy, as values for scan accuracy can vary substantially, depending on the system used and the geometry of the scanned item $[5,41]$. However, the geometric conditions were the same for all groups and should not have affected the scanning accuracy between the groups. Additionally, some rounding effects may occur when scanning sharp edges; this limits the efficiency of margin evaluation. For this reason, an additional evaluation step with visual examination was performed. Undoubtedly, powdering increases the measuring error for digital surfacing [42]. Yet, without powdering, accurate scanning is not possible. However, the evaluation method yielded highly reproducible results $(11 \pm 7 \mu \mathrm{m})$, taking into account the inaccuracy caused by powdering, scanning and the deviations occurring during superimposition. Therefore, the quality of the fabrication process of each machine could be evaluated very precisely.

By directly comparing the milled surface to the originally calculated surface, it was possible to evaluate the milling procedure in a single attempt. In contrast, when measuring marginal or internal gaps, the fit of the restoration can influence the results. Therefore, the previous findings of marginal $[9$, 26] and internal gap measurements [11, 12, 23, 27, 28] cannot be compared with the findings of this study. The present results are comparable with the results of Bosch et al., which used a similar approach [17]. They found that five-axis milling delivers high trueness and allows a more effective milling of surfaces close to the insertion axis [17]. Steep walls and small angles can be machined from different directions to provide a better outcome. Five-axis machining is mostly used in labside fabrication. It may have been expected that the labside milling devices, group IMES and group X5, would perform better than the chairside milling procedures in group MCXL and group MCXL-EF, as five-axis machining is available for both these labside devices. However, the chairside milling in group MCXL-EF provides results similar to those of group IMES and group X5. The advantages of five-axis machining may not play a major effect when grinding or milling single-unit fullanatomic restorations. Machining multi-unit restorations might cause other results because the different insertion axes and undercuts can be approached more flexible with five-axis milling units.

Milling strategy of group IMES and group X5 uses different instruments with one spindle in z-direction sweeping the restoration according to $2 \mathrm{D}$ curves analogue to contour lines. Groups MCXL and MCXL-EF use two spindles, grinding simultaneously from both sides, in a U-shaped movement. Additionally, two separate milling cycles are performed where the second cycle removes only $300 \mu \mathrm{m}$ of residual material at all surfaces left from the first milling cycle [17].

One additional advantage of industry-based five-axis milling units is the possibility of using instruments with different geometry with one motor spindle to provide optimal machining. In contrast to group MCXL, which uses the same
Fig. 1 Difference images of an onlay fabricated with different processes. a IMES. b MCXL. c MCXL-EF. d X5. The deviation range is colour-coded from $-50 \mu \mathrm{m}$ (purple) to $+50 \mu \mathrm{m}$ (red) . A negative deviation (purple) indicates less removal of material during the milling, while a positive deviation (red) indicates more removal of material compared to the digital-calculated restoration dimensions

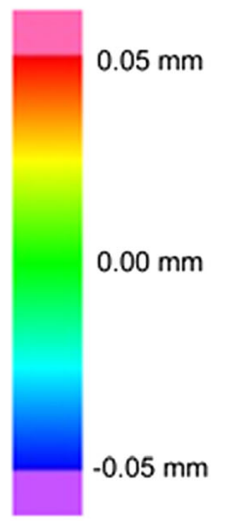



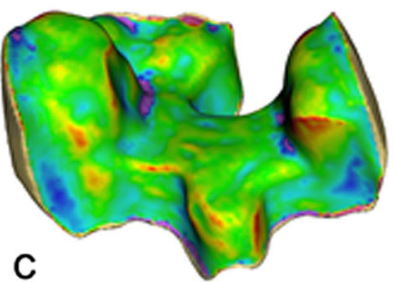




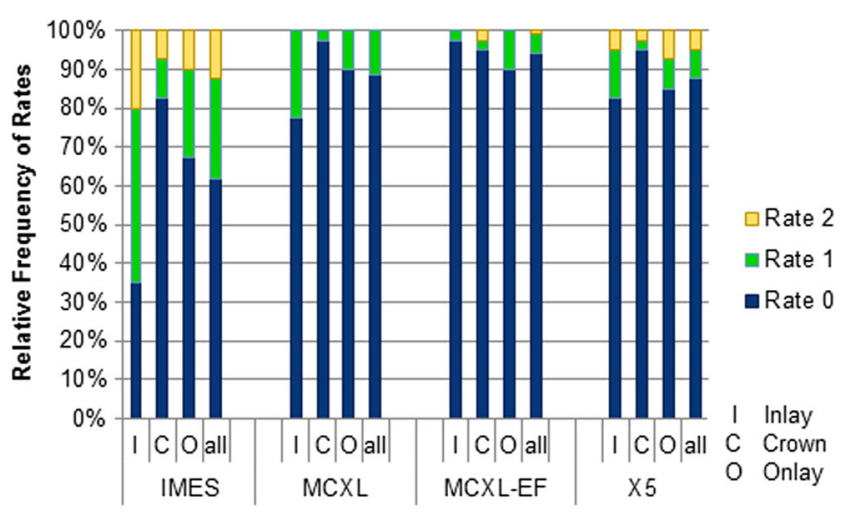

Fig. 2 Relative frequency of marginal chipping rates of inlays, crowns, onlays and all restorations for milling groups IMES, MCXL, MCXL-EF and X5. Rate $0:<50 \mu \mathrm{m}$, rate $1: 50-100 \mu \mathrm{m}$, rate $2:>100 \mu \mathrm{m}$

instrument geometry for both milling cycles, group MCXLEF uses instruments with a smaller diameter for the second milling cycle. This implementation to the four-axis chairside milling unit results in a significantly higher milling accuracy. The diameter of the used instrument affects the outcome of the milling process. If the instrument diameter exceeds the dimensions of curves in the preparation, unwanted cavities are produced [3]. The larger the diameter of the rotary instrument, the larger the cavities become. This may be a reason for the less accurate milling results in group MCXL than in the other three groups.

An interesting observation was the chipping at marginal areas, which was mostly problematic for inlay and onlay restorations. The best results were seen in group MCXL-EF and group MCXL, but Group IMES did not perform as well as the other groups. This may be because the milling strategy had not yet been finally optimized and did not provide special protection of marginal areas. Yet, the manufacturer's recommended milling strategy for glass ceramic was used, without manual changes to the milling parameters. Glass ceramics are often used in single tooth treatment and milling should result in sufficient marginal quality when using this material. As glass ceramic is more prone to chipping than other materials [43]; it should illustrate machining problems very clearly. The restriction to one milling material (VITABLOCS Mark II) in this study was considered reasonable, as different materials could be milled with different results even when using the same milling device.

The remaining sprue in group IMES was larger than that in the other three groups, which is disadvantageous, since its removal requires more time and shape correction. Milling time for group X5 and for group IMES was longer than that for groups MCXL and MCXL-EF. One reason for this difference is that the milling processes differ between the labside and chairside devices. While the labside devices use only one instrument at a time, the chairside devices simultaneously mill the inner and occlusal surface using two instruments. Therefore, the labside devices require an instrument change, as the instruments are used sequentially, whereas the instruments do not have to be changed for the chairside devices. In summary, the milling time for groups MCXL and MCXL-EF is more practical for chairside production. Although additional time is needed for group MCXLEF than for group MCXL, the better milling results should outweigh this drawback, as less time should be required for manual adjustments prior to insertion. Furthermore, the occlusal and approximal contact points can be better predicted, with restorations fitting well from the start, so that less manual correction of occlusal contacts is subsequently necessary.

\section{Conclusions}

Within the limitations of this present study, it can be concluded that five-axis milling devices show high trueness. The MCXL extra-fine mode showed similar good results and offers the possibility of chairside fabrication with milling results comparable to those of five-axis milling units, and requiring less milling time.

\section{Compliance with ethical standards}

Conflict of interest The authors declare that they have no conflict of interest.

Funding This study was not funded.

Ethical approval All procedures performed in this study involving human participants were in accordance with the ethical standards of the institutional and national research committee and with the 1964 Helsinki declaration and its later amendments or comparable ethical standards.

Informed consent Informed consent was obtained from all individual participants included in the study.

\section{References}

1. Anadioti E, Aquilino SA, Gratton DG, et al. (2014) 3D and 2D marginal fit of pressed and CAD/CAM lithium disilicate crowns made from digital and conventional impressions. J Prosthodont 23: 610-617. doi:10.1111/jopr.12180

2. Tapie L, Lebon N, Mawussi B, Fron Chabouis H, Duret F, Attal JP (2015) Understanding dental CAD/CAM for restorations - the digital workflow from a mechanical engineering viewpoint. Int $\mathrm{J}$ Comput Dent 18:21-44

3. Tinschert J, Natt G, Hassenpflug S, Spiekermann H (2004) Status of current $\mathrm{CAD} / \mathrm{CAM}$ technology in dental medicine. Int J Comput Dent 7:25-45 
4. Ender A, Mehl A (2015) In-vitro evaluation of the accuracy of conventional and digital methods of obtaining full-arch dental impressions. Quintessence Int 46:9-17. doi:10.3290/j.qi.a32244

5. Luthardt RG, Loos R, Quaas S (2005) Accuracy of intraoral data acquisition in comparison to the conventional impression. Int $\mathrm{J}$ Comput Dent 8:283-294

6. Mehl A, Ender A, Mormann W, Attin T (2009) Accuracy testing of a new intraoral 3D camera. Int J Comput Dent 12:11-28

7. Ziegler M (2009) Digital impression taking with reproducibly high precision. Int J Comput Dent 12:159-163

8. Mehl A (2012) A new concept for the integration of dynamic occlusion in the digital construction process. Int J Comput Dent 15: $109-123$

9. Contrepois M, Soenen A, Bartala M, Laviole O (2013) Marginal adaptation of ceramic crowns: a systematic review. J Prosthet Dent 110:447-454.e10. doi:10.1016/j.prosdent.2013.08.003

10. Hmaidouch R, Neumann P, Mueller WD (2011) Influence of preparation form, luting space setting and cement type on the marginal and internal fit of $\mathrm{CAD} / \mathrm{CAM}$ crown copings. Int J Comput Dent $14: 219-226$

11. Nakamura T, Dei N, Kojima T, Wakabayashi K (2003) Marginal and internal fit of Cerec $3 \mathrm{CAD} / \mathrm{CAM}$ all-ceramic crowns. Int $\mathrm{J}$ Prosthodont 16:244-248

12. Lee KB, Park CW, Kim KH, Kwon TY (2008) Marginal and internal fit of all-ceramic crowns fabricated with two different CAD/ CAM systems. Dent Mater J 27:422-426

13. Kosyfaki P, del Pilar Pinilla Martin M, Strub JR (2010) Relationship between crowns and the periodontium: a literature update. Quintessence Int 41:109-126

14. Yuksel E, Zaimoglu A (2011) Influence of marginal fit and cement types on microleakage of all-ceramic crown systems. Braz Oral Res 25:261-266

15. Baig MR, Tan KB, Nicholls JI (2010) Evaluation of the marginal fit of a zirconia ceramic computer-aided machined (CAM) crown system. J Prosthet Dent 104:216-227. doi:10.1016/S0022-3913(10)60128-X

16. Sax C, Hämmerle CH, Sailer I (2011) 10-year clinical outcomes of fixed dental prostheses with zirconia frameworks. Int J Comput Dent 14:183-202

17. Bosch G, Ender A, Mehl A (2014) A 3-dimensional accuracy analysis of chairside CAD/CAM milling processes. J Prosthet Dent 112: 1425-1431. doi:10.1016/j.prosdent.2014.05.012

18. Kohorst P, Butzheinen LO, Dittmer MP, Heuer W, Borchers L, Stiesch M (2010) Influence of preliminary damage on the loadbearing capacity of zirconia fixed dental prostheses. J Prosthodont 19:606-613. doi:10.1111/j.1532-849X.2010.00640.x

19. Hamza TA, Ezzat HA, El-Hossary MM, Katamish HA, Shokry TE, Rosenstiel SF (2013) Accuracy of ceramic restorations made with two CAD/CAM systems. J Prosthet Dent 109:83-87. doi:10.1016/S0022-3913(13)60020-7

20. Kuhn K, Ostertag S, Ostertag M, Walter MH, Luthardt RG, Rudolph H (2015) Comparison of an analog and digital quantitative and qualitative analysis for the fit of dental copings. Comput Biol Med 57:32-41. doi:10.1016/j.compbiomed.2014.11.017

21. Luthardt RG, Bornemann G, Lemelson S, Walter MH, Huls A (2004) An innovative method for evaluation of the 3-D internal fit of $\mathrm{CAD} / \mathrm{CAM}$ crowns fabricated after direct optical versus indirect laser scan digitizing. Int J Prosthodont 17:680-685

22. Moldovan O, Luthardt RG, Corcodel N, Rudolph H (2011) Threedimensional fit of CAD/CAM-made zirconia copings. Dent Mater 27:1273-1278. doi:10.1016/j.dental.2011.09.006

23. Mously HA, Finkelman M, Zandparsa R, Hirayama H (2014) Marginal and internal adaptation of ceramic crown restorations fabricated with $\mathrm{CAD} / \mathrm{CAM}$ technology and the heat-press technique. J Prosthet Dent 112:249-256. doi:10.1016/j.prosdent.2014.03.017
24. Schaefer O, Kuepper H, Thompson GA, Cachovan G, Hefti AF, Guentsch A (2013) Effect of CNC-milling on the marginal and internal fit of dental ceramics: a pilot study. Dent Mater 29:851858. doi:10.1016/j.dental.2013.04.018

25. Morris HF (1992) Department of Veterans Affairs Cooperative Studies Project No. 242. Quantitative and qualitative evaluation of the marginal fit of cast ceramic, porcelain-shoulder, and cast metal full crown margins. Participants of CSP no. 147/242. J Prosthet Dent 67:198-204

26. Nawafleh NA, Mack F, Evans J, Mackay J, Hatamleh MM (2013) Accuracy and reliability of methods to measure marginal adaptation of crowns and FDPs: a literature review. J Prosthodont 22:419-428. doi:10.1111/jopr.12006

27. Anadioti E, Aquilino SA, Gratton DG, et al. (2015) Internal fit of pressed and computer-aided design/computer-aided manufacturing ceramic crowns made from digital and conventional impressions. J Prosthet Dent 113:304-309. doi:10.1016/j.prosdent.2014.09.015

28. Brawek PK, Wolfart S, Endres L, Kirsten A, Reich S (2013) The clinical accuracy of single crowns exclusively fabricated by digital workflow - the comparison of two systems. Clin Oral Investig 17: 2119-2125. doi:10.1007/s00784-013-0923-5

29. Gassino G, Barone Monfrin S, Scanu M, Spina G, Preti G (2004) Marginal adaptation of fixed prosthodontics: a new in vitro 360degree external examination procedure. Int J Prosthodont 17:218223

30. Kohorst P, Brinkmann H, Li J, Borchers L, Stiesch M (2009) Marginal accuracy of four-unit zirconia fixed dental prostheses fabricated using different computer-aided design/ computer-aided manufacturing systems. Eur J Oral Sci 117: 319-325. doi:10.1111/j.1600-0722.2009.00622.x

31. Pelekanos S, Koumanou M, Koutayas SO, Zinelis S, Eliades G (2009) Micro-CT evaluation of the marginal fit of different InCeram alumina copings. Eur J Esthet Dent 4:278-292

32. Holst S, Karl M, Wichmann M, Matta RE (2011) A new triple-scan protocol for 3D fit assessment of dental restorations. Quintessence Int 42:651-657

33. Schaefer O, Decker M, Wittstock F, Kuepper H, Guentsch A (2014) Impact of digital impression techniques on the adaption of ceramic partial crowns in vitro. J Dent 42:677-683. doi:10.1016/j. jdent.2014.01.016

34. Schaefer O, Kuepper H, Sigusch BW, Thompson GA, Hefti AF, Guentsch A (2013) Three-dimensional fit of lithium disilicate partial crowns in vitro. J Dent 41:271-277. doi:10.1016/j. jdent.2012.11.014

35. Schaefer O, Watts DC, Sigusch BW, Kuepper H, Guentsch A (2012) Marginal and internal fit of pressed lithium disilicate partial crowns in vitro: a three-dimensional analysis of accuracy and reproducibility. Dent Mater 28:320-326. doi:10.1016/j. dental.2011.12.008

36. Zaruba M, Ender A, Mehl A (2014) New applications for threedimensional follow-up and quality control using optical impression systems and OraCheck. Int J Comput Dent 17:53-64

37. Kim KB, Kim JH, Kim WC, Kim JH (2014) Three-dimensional evaluation of gaps associated with fixed dental prostheses fabricated with new technologies. J Prosthet Dent 112:1432-1436. doi:10.1016/j.prosdent.2014.07.002

38. Tapie L, Lebon N, Mawussi B, Fron-Chabouis H, Duret F, Attal JP (2015) Understanding dental CAD/CAM for restorations - accuracy from a mechanical engineering viewpoint. Int J Comput Dent 18:343-367

39. Lebon N, Tapie L, Duret F, Attal JP (2016) Understanding dental CAD/CAM for restorations-dental milling machines from a mechanical engineering viewpoint. Part A: chairside milling machines. Int J Comput Dent 19:45-62

40. Ahlers MO, Morig G, Blunck U, Hajto J, Probster L, Frankenberger R (2009) Guidelines for the preparation of 
$\mathrm{CAD} / \mathrm{CAM}$ ceramic inlays and partial crowns. Int J Comput Dent 12:309-325

41. Ender A, Zimmermann M, Attin T, Mehl A (2015) In vivo precision of conventional and digital methods for obtaining quadrant dental impressions. Clin Oral Investig. doi:10.1007/s00784-015-1641-y

42. Rudolph H, Luthardt RG, Walter MH (2007) Computer-aided analysis of the influence of digitizing and surfacing on the accuracy in dental CAD/CAM technology. Comput Biol Med 37:579-587. doi:10.1016/j.compbiomed.2006.05.006

43. Quinn GD, Giuseppetti AA, Hoffman KH (2014) Chipping fracture resistance of dental CAD/CAM restorative materials: part I-procedures and results. Dent Mater 30:e99-e111. doi:10.1016/j. dental.2014.02.010 